\title{
The Connection between Extreme Precipitation Variability over Monsoon Asia and Large-Scale Circulation Patterns
}

\author{
Sunilkumar Khadgarai ${ }^{1}$ (D), Vinay Kumar ${ }^{2, *}$ (i) and Prabodha Kumar Pradhan ${ }^{3}$ (I) \\ 1 Indian Institute of Tropical Meteorology (IITM), Ministry of Earth Sciences, Pune 411008, India; \\ sunil.khadgarai@tropmet.res.in \\ 2 Department of Environmental Engineering, Texas A\&M University, Kingsville, TX 78363, USA \\ 3 Department of Physics, Sri Venkateswara University, Tirupati 517502, India; prabodha.svu@gmail.com \\ * Correspondence: neelubijnori@gmail.com or vinay.kumar@tamuk.edu; Tel.: +1-850-570-2694
}

Citation: Khadgarai, S.; Kumar, V.; Pradhan, P.K. The Connection between Extreme Precipitation Variability over Monsoon Asia and Large-Scale Circulation Patterns. Atmosphere 2021, 12, 1492. https:// doi.org/10.3390/atmos12111492

Academic Editor: Daniel Argüeso

Received: 14 September 2021

Accepted: 4 November 2021

Published: 11 November 2021

Publisher's Note: MDPI stays neutral with regard to jurisdictional claims in published maps and institutional affiliations.

Copyright: (c) 2021 by the authors. Licensee MDPI, Basel, Switzerland. This article is an open access article distributed under the terms and conditions of the Creative Commons Attribution (CC BY) license (https:// creativecommons.org/licenses/by/ $4.0 /)$.

\begin{abstract}
Spatial and temporal variability in precipitation has been dramatically changed due to climate variability and climate change over the global domain. Increasing in extreme precipitation events are pronounced in various regions, including monsoon Asia (MA) in recent decades. The present study evaluated precipitation variability in light of intensity, duration, and frequency with several extreme precipitation climate change indices developed by the Expert Team on Climate Change Detection Indices (ETCCDI) over the MA region. This study uses an improved version (APHRO_V1901) of the Asian Precipitation Highly Resolved Observation Data Integration Towards Evaluation of extreme events (APHRODITE-2) gridded rainfall product. Results showed that the spatial variability of the extreme precipitation climate change indices is reflected in the annual mean rainfall distribution in MA. Maximum one-day precipitation $(R \times 1)$ and precipitation contributed from extremes (R95) depict a peak in decadal mean rainfall values over topography regions. A significant positive trend in $\mathrm{R} \times 1$ (with a slope of $0.3 \mathrm{~mm} / \mathrm{yr}$ ) and precipitation greater than the 95th percentile (R95: with a slope of $0.5 \mathrm{~mm} / \mathrm{yr}$ ) are predominantly observed in decadal trends in regional average extreme precipitation climate change indices over MA. Maritime continental countries exhibit an inclined trend in R10, whereas central Asian arid regions show a decreasing tendency in continuous dry days (CDD). The positive trend in R95 is observed over central India, the monsoon region in China, countries that reside over the equator and some parts of Japan, and the Philippines. When comparing the influence of surface temperature $(\mathrm{T})$ and total column water vapor (TCW) on precipitation climate change indices, TCW seems to be a crucial attributor to climate change indices meridional variability. The mutual correlation analysis depicts that precipitation contributed from extremes (R95) strongly correlates in terms of temporal variability with all extreme precipitation indices. Among various global circulation patterns, the prevalent conditions of sea surface temperature (SST) over the equatorial Pacific Ocean have a significant influence on decadal variability in extreme precipitation climate change indices. R10 and R95 possess a relatively significant correlation (0.86 and 0.91) with the Southern Oscillation Index. The maximum number of consecutive dry days (CDD) shows an increasing trend with a positive phase of the North Atlantic Oscillation Index.
\end{abstract}

Keywords: climate change indices; extreme precipitation; APHRODITE; monsoon Asia

\section{Introduction}

Climate change and its socio-economic impacts are the most concerning and challenging issues for several international and national organizations in the global domain. The sustained impact of climate change has modulated biodiversity and the ecosystem at multiple scales on Earth [1]. A comprehensive understanding of climate variability and reliable future projections are essential to adapt climate change and mitigation challenges. However, the complex interaction between human-induced climate change and natural variability imposes constraints for evaluating climate variability [2]. The direct and indirect 
effect of the changing climate and its consequences on the global domain, continental scale, and regional scale is still a subject of open discussion. The profound signal of climate change and variability is clearly evidenced by an increase in the number of extreme precipitation events, flash floods, droughts, and heatwaves in recent decades [3-5]. Of particular concern, the increase in extreme precipitation events is reasonably associated with an increase in mean global temperature. The increase in mean global temperature enhances water vapor holding capacity in the atmosphere and results in variations in precipitation over short time intervals [6].

In general, extreme precipitation events are caused by various atmospheric phenomena such as mesoscale convective systems, atmospheric rivers, cloud bursts, and cyclones. The excess moisture availability in the atmosphere in addition to surface temperature conditions and geographical attributes such as topography are responsible for extreme precipitation events. Extreme precipitation events cause significant damages to society and loss of properties [7]. As flash floods are strongly associated with unexpected heavy deluges, they also often lead to vector-borne diseases. Moreover, climate change is greatly reflected in the extreme precipitation rather than mean precipitation over the global domain [6]. Hence, numerous researchers pay attention to better understand the trends/variability of extreme precipitation events in the wake of climate change. Several previous studies investigated the decadal changes in precipitation patterns and possible associated driving mechanisms [8-11]. The observed change in precipitation patterns is closely associated with several aspects: the state of the large-scale circulation patterns, surface temperature conditions, higher total column water vapor, and advected water vapor flux.

Several earlier researchers developed their criteria in terms of "indices" to predict regional precipitating systems. For instance, some of the well-known monsoon indices used to indicate the South Asian monsoon based on the intensity of the wind at two vertical levels $(850 \mathrm{hPa}$ and $200 \mathrm{hPa})$, over the Indian subcontinent such as the Webster-Yang Monsoon Index, Indian Monsoon Index, and Extended Indian Monsoon Rainfall, respectively. To understand the nature of the precipitation variability in the light of intensity, duration, and frequency, the Expert Team on Climate Change Detection Indices (ETCCDI), under the guidance of the World Meteorological Organization (WMO), developed 27 climate change indices for precipitation and temperature and the details are discussed in [12]. These indices have been proven to be a proxy for quantifying the changes in precipitation and temperature patterns and used for monsoon Asia [13]. These indices also possess potential applications prominently for addressing the impact of climate change on precipitation and temperature.

It is clearly evidenced from earlier studies that rainfall and temperature witnessed significant changes, often in the extreme ends on global, continental, and regional scales. However, rainfall does not follow similar trends like other parameters, and instead depicts positive/negative trends over different regions in the global domain [14]. Moreover, the impact of climate change on rainfall trends is compared to be insignificant with other parameters such as temperature, as reported in [15]. Though the observed trends are either significant or insignificant, they significantly impact the precipitation relevant aspects such as freshwater availability, soil moisture conditions, groundwater discharge, etc. Therefore, further quantification of the precipitation variability in terms of intensity, duration, and persistence certainly enhances our understanding of how climate change impacts extreme precipitation events. Thus, such attempts help to design and develop climate change adaptation systems.

As monsoon Asia is concerned, several studies investigated the possible changes in extreme precipitation and temperature patterns [16-26]. The aforementioned studies focused on detecting the trends in climate change indices mostly over large land regions such as India, China, and central Asia. A clear transition in wet day frequency and number of continuous wet days are observed over a large part of central India during the two study periods [22]. Their study also highlights the predominant remote influence of equatorial Indian SST on precipitation indices. Kumar et al. (2020) [22] detected decadal trends in 
precipitation and temperature and also projected trends in temperature under the RCP 8.5 scenario using CanESM2 data. Mixed trends in precipitation amount from extremes (R95) and projected increase in warm nights are observed over a varying fraction of locations in India. Over China and central Asia, previous studies $[20,23]$ investigated the trends in extreme precipitation and temperature indices using surface-based observations, gridded datasets, and evaluated the gridded dataset, Global Precipitation Climatology Centre (GPCC) with surface observations. The increasing trends in precipitation-based climate change indices and decrease in continuous dry days are the important findings from these studies. Comparing the gridded datasets with station average values highlighted the potential use of the GPCC dataset in extreme precipitation analysis while considering extreme precipitation analysis over the global domain. Further, [21,25] evaluated extreme precipitation variability on a global scale using observations (Daily Precipitation Observations for Climate prediction-DAPACLIP) and model approaches (CMIP6 and CMIP5). They showed different climatological features such as tropical storm paths, orographic effects, and monsoon processes. They suggested that how interpolation errors and gauge density can influence the representation of extreme precipitation events. The improvements in CMIP6 models are reflected while simulating extreme precipitation more strongly, reducing the dry biases over tropical and subtropical rain band regions.

Most of the previous studies are region-specific and hardly discussed the influence of large-scale circulation patterns on extreme precipitation climate change indices over MA. The major constraint to conduct such trend analysis on a continental scale is the lack of publicly accessible high-resolution datasets. The detected trends are possibly connected with the state of large-scale circulation patterns and the influence of such large-scale patterns (such as ENSO) not only extends specific regions but also spreads to continental scale. Therefore, a detailed study on the possible link between regional trends under the influence of large-scale climate patterns is worth attempting. Moreover, numerous studies emphasized that climate change remarkably altered the precipitation patterns over other MA regions rather than the SE region, China, and India [27]. In addition, other relevant possible aspects, such as the influence of total column water vapor in the atmosphere and surface temperature conditions on extreme precipitation climate change indices variability, are not yet addressed over the MA region. Thus, the novelty of the present research is to quantify the regional variability and recent trends of extreme precipitation climate change indices in the past two decades and the dominant remote influence of large-scale circulation patterns on different extreme precipitation climate change indices. We also aim to evaluate quantitatively the influence of meridional variability of surface temperature $(\mathrm{T})$ and total column water vapor (TCW) on precipitation climate change indices. Further understanding of extreme precipitation variability over MA and possible controlling factors such as largescale circulation patterns, and TCW certainly supports the development of mitigation challenges and further improves the prediction skill of extreme precipitation events.

Although climate change and its profound consequences have been witnessed for several decades, the impact of climate change has intensified in the last two decades as reported in $[20,21,28]$. For instance, the top ten warmest years since 1880, record greenhouse gas emissions, acceleration of global sea level, decline in sea ice, and increased number of high-impact weather events have been observed in the last two decades. Previous studies also emphasized significant changes in precipitation patterns during the last two decades over MA [29,30]. Therefore, the present study aims to investigate the possible changes in precipitation extremes and associated teleconnections over the MA domain in the past two decades (1998-2015).

\section{Materials and Methods}

\subsection{Study Region}

The MA region is known for its diversity in different rainfall regimes and geographical features. The study region is extended between longitude $\left(60^{\circ} \mathrm{E}-150^{\circ} \mathrm{E}\right)$ and latitude $\left(15^{\circ} \mathrm{S}-55^{\circ} \mathrm{N}\right)$. Various synoptic-scale monsoon circulation phenomena bring annual rain- 
fall over different geographical regions in MA (Figure 1). For instance, the Indian subcontinent receives a significant rainfall fraction during the southwest monsoon season [31]. Japan receives rainfall during the Baiu season and due to the number of frontal systems [32]. Meanwhile, the Philippines gets annual rainfall from two distinct seasons [32]. Countries that reside over the equatorial belt receive a significant amount of rainfall from convective systems. In addition to such large-scale monsoonal circulation in MA regions, local geographical features such as topography also play a significant role in enhancing rain-bearing mechanisms. Such a kind of orography effect on precipitating systems is seen along the Western Ghats of India, the Arakan Mountains in Myanmar, and the Japanese Alps in Japan. Apart from its diversity in geographical features, coastal regions are vulnerable to tropical cyclone activities. For example, the southeastern belt of Indian Territory, the entire coastal belt of Philippines, and Japan.

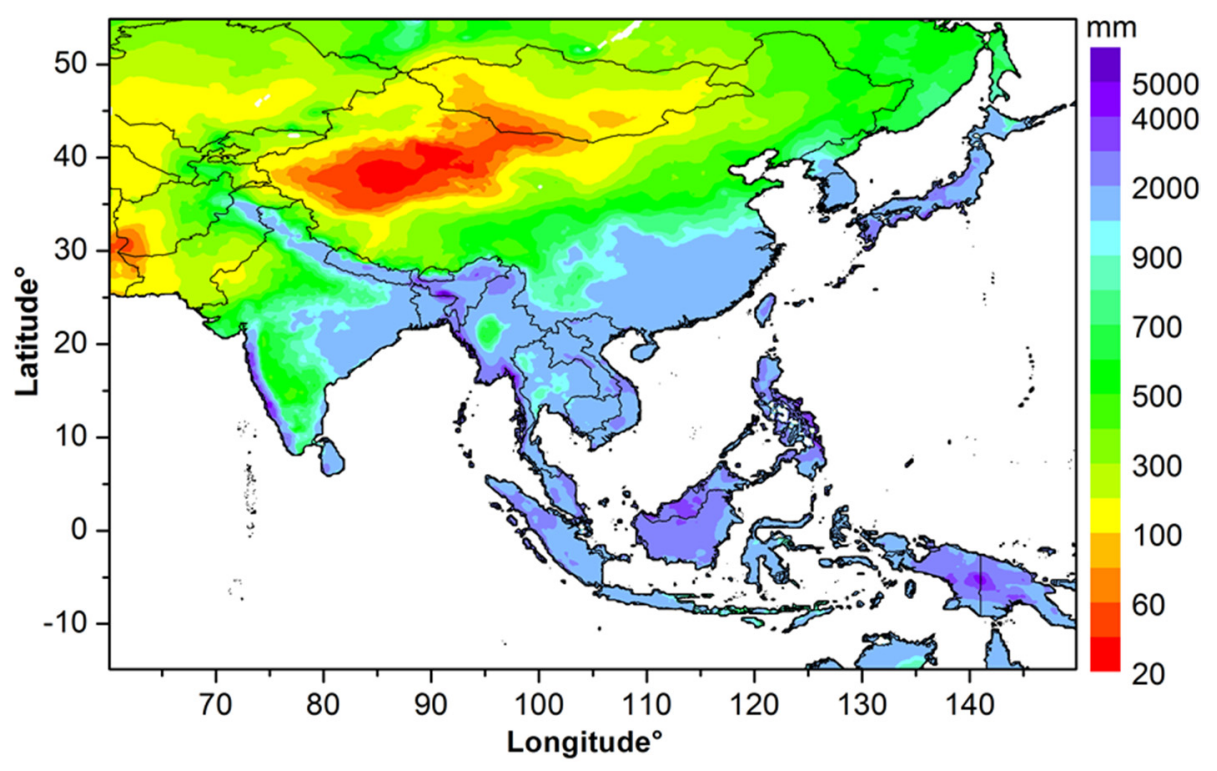

Figure 1. Spatial distribution of mean annual rainfall (1998-2015) over monsoon Asia (MA).

The diverse geography, coupled with complex topography, results in inhomogeneous rainfall distribution over MA. Several distinct climate zones, such as tropical core convective zones to cold subtropical regions, possess contrasting rainfall regimes in MA. The chaotic nature of land-ocean interactions over MA further makes rainfall patterns much complex [33].

\subsection{APHRODITE Datasets}

\subsubsection{Rainfall}

Asian Precipitation Highly Resolved Observational Data Integration Towards Evaluation of Extremes (APHRODITE-2) is an open data source available to the public domain for various research applications. APHRODITE-1 primarily focused on water resource management, improving model outputs, and reference datasets to validate model/satellite outputs/estimates. APHRODITE-2 is a daily gridded rain gauge dataset available for 18 years from 1998 to 2015 with a spatial resolution of a quarter degree over the monsoon Asia region. Data source and generation methodology are discussed in Yatagai et al. (2012) [34]. The advantages of APHRODITE data in various hydro/meteorological applications have been evaluated by several earlier researchers [35,36]. Observations inferred that APHRODITE is able to represent temporal variability, probability of detection, and frequency of extreme precipitation events as observed by rain gauge measurements over different regions in MA. However, the lack of adequate surface rain gauge measurements over high altitude regions makes APHRODITE datasets less reliable. The latest version of APHRODITE assures an improvement over topography regions with the latest climatology 
developed by APHRODITE-2. The APHRODITE-2 team made several reasonable efforts, such as refining the quality control procedure to control false measurements, end of the day (EOD) correction to avoid any inconsistency in data accumulation time, and station value conservation to improve the representation of extreme rainfall measurements over individual grids in the V1901 product [32,37]. Extreme rainfall evaluation under the global climate change scenario is a crucial aspect of the APHRODITE-2 program. Hence, this study has considered an improved version of the APHRODITE-2 dataset (APHRO_V1901) to evaluate extreme precipitation events over the Monsoon Asian region. The dataset was acquired from [38] for 1998-2015.

\subsubsection{Temperature}

APHRODITE also provides daily mean temperature measurements with a resolution of a quarter degree over the MA region for the period of 1961-2015. The latest version (V1808) of the temperature product is available with significant improvements such as the introduction of the topographic effect in spatial interpolation, improvement in interpolation algorithm, and climatology representation. Additional datasets are added over south-Asian countries such as India, Bhutan, Myanmar, and Thailand. The details of this dataset and methodology are discussed in Yasutomi et al. (2011) [39].

\subsection{MAIAC Water Vapor}

MODerate resolution Imaging Spectrometer (MODIS) water vapor products have been extensively used for regional and global analysis [40-42]. MODIS is a multispectral sensor onboard the North America Space Administration's (NASA's) Terra and Aqua satellites since 2000 and 2002, respectively. Terra and Aqua operate sun-synchronously, and Terra crosses the equator at 10:30 local time (LT) while Aqua crosses the equator at 13:30 LT. This multispectral sensor provides 36 bands, 3 resolutions (250, 500, and $1000 \mathrm{~m}$ ), and near-daily observations with a broad swath $(2330 \mathrm{~km})$. The MODIS Collection 6.1 provides a new water vapor product (MCD19A2) derived from Multi-Angle Implementation for Atmospheric Correction (MAIAC). The algorithm uses three spectral channels (MODIS B17 $(890-920 \mathrm{~nm})$, B18 $(931-941 \mathrm{~nm})$, and B19 $(915-965 \mathrm{~nm})$ ) to retrieve the total water transmittance and estimate the CWV using Look Up Tables (LUT) procedures. The global validation of this product shows a high agreement between MAIAC/AERONET CWV retrieval (correlation > 0.95) and the expected error lower than 15\% [43]. A detailed description of the MAIAC CWV algorithm is found in [44]. This study used the MCD19A2 product (2002-2015) to calculate the long-term monthly average of total column water vapor over the MA region. The product is available at Level-1 and Atmosphere Archive \& Distribution System (LAADS) Distributed Active Archive Center (DAAC) [45]. The daily Aqua MODIS products were extracted from MCD19A2 HDF files, and cloud-free retrievals were filtered using the quality assurance layer from SDS "AOD_QA". By using high-quality retrievals, we computed the monthly average water vapor between 2002 and 2015.

\subsection{Extreme Precipitation Climate Change Indices}

ETCCDI defined 27 different climate change indices based on daily precipitation amounts and temperature to detect and monitor climate change [12]. Among eleven precipitation-based climate change indices, we have acquired seven climate change indices to investigate the nature of precipitation variability in light of intensity, duration, and frequency based on a high-quality daily gridded precipitation available in the MA region. The intensity/duration/frequency of extreme precipitation events are represented by the $\mathrm{R} \times 1, \mathrm{R} \times 5, \mathrm{R} 95, \mathrm{SDII} / \mathrm{CWD}$, and CDD/R10 indices. The basic criteria for selecting these seven out of 10 indices is drawn from the definition of the indices. For example, R10, R20, or $\mathrm{RN}$ represent the number of precipitation events with $10 \mathrm{~mm}, 20 \mathrm{~mm}$, or $\mathrm{N} \mathrm{mm}$. The detailed definitions and units of climate change indices are described in Table 1. 
Table 1. Definition, estimation methodology of precipitation climate change indices and their units [12].

Details of Estimation Methodology of Precipitation Climate Change Indices and Units

Rx1day: Monthly maximum 1-day precipitation: Let $R_{\mathrm{ij}}$ be the daily precipitation amount on day $i$ in period $j$. The maximum 1-day value for period $j$ are: $R x 1 d a y_{j}=\max \left(R R_{i j}\right)$, units $=m m$.

Rx5day: Monthly maximum consecutive 5-day precipitation: Let $R_{\mathrm{kj}}$ be the precipitation amount for the 5 -day interval ending ${ }_{k}$, period $\mathrm{j}$. Then maximum 5-day values for period $\mathrm{j}$ are: $R \times 5$ day $_{j}=\max \left(R_{k j}\right)$, units $=\mathrm{mm}$.

SDII: Simple precipitation intensity index: Let $R_{\mathrm{wj}}$ be the daily precipitation amount on wet days, $w(R R \geq 1 \mathrm{~mm})$ in period $j$. If $W$ represents the number of wet days in $j$, then:

$$
\mathrm{SDII}_{\mathrm{j}}=\frac{\sum_{\mathrm{w}=1}^{\mathrm{W} R \mathrm{Rj}}}{\mathrm{W}} \text {, units }=\mathrm{mm} / \text { day. }
$$

R10mm: Annual count of days when PRCP $\geq 10 \mathrm{~mm}$ : Let $R_{\mathrm{ij}}$ be the daily precipitation amount on day $i$ in period $j$. Count the number of days where: $R R_{i j} \geq 10 \mathrm{~mm}$. units $=$ days.

CDD: Maximum length of dry spell, maximum number of consecutive days with $\mathrm{RR}<1 \mathrm{~mm}$ : Let $\mathrm{RR}_{\mathrm{ij}}$ be the daily precipitation amount on day $\mathrm{i}$ in period $\mathrm{j}$. Count the largest number of consecutive days where: $\mathrm{RR}_{\mathrm{ij}}<1 \mathrm{~mm}$ units = days.

CWD: Maximum length of wet spell, maximum number of consecutive days with $R R \geq 1 \mathrm{~mm}$ : Let $R_{\mathrm{ij}}$ be the daily precipitation amount on day $i$ in period $j$. Count the largest number of consecutive days where: $R_{\mathrm{ij}} \geq 1 \mathrm{~mm}$ units = days.

R95pTOT: Annual total PRCP when $R R>95 p$. Let $R_{w j}$ be the daily precipitation amount on a wet day $w(R R \geq 1.0 \mathrm{~mm})$ in period $i$ and let $R R_{w n} 95$ be the 95 th percentile of precipitation on wet days in the 1961-1990 period. If $W$ represents the number of wet days in the period, then: $\mathrm{R} 95_{\mathrm{PJ}}=\sum_{\mathrm{w}=1}^{\mathrm{W}} \mathrm{RR}_{\mathrm{wj}}$ where $\mathrm{RR}_{\mathrm{wj}}>\mathrm{RRwn} 95$. Units $=\mathrm{mm}$.

\subsection{Global Teleconnections and Regional Scale Monsoon Indices}

As evidenced by earlier literature, the spatiotemporal variability of rainfall in the MA region has a prominent association with large-scale circulations [46]. Often, the nature of climate change and variability is reflected by the strengthening/weakening of such large-scale circulations. As an example, the recent weakening of monsoonal circulation over the Indian subcontinent [23]. Thus, the influence of large-scale circulation patterns on precipitation climate change indices reveals the possible linkage between precipitation patterns and teleconnections. We have considered nine such circulation patterns, namely Arctic Oscillation (AO), Atlantic Multi-decadal Oscillation (AMO), Dipole Mode Index (DMI), El-Niño Modoki Index (EMI), East-Central Tropical Pacific SST (Nino 3.4), Pacific Decadal Oscillation (PDO), Southern Oscillation Index (SOI), Multivariate ENSO Index (MEI V2), North Atlantic Oscillation (NAO), and Madden Julian Oscillation (MJO). The detailed description and estimation of most of these indices can be found by [47]. DMI and EMI data can be obtained on the JAMSTEC website [48]. The MJO amplitude and Real-time Multivariate MJO Index (RMM1 and RMM2) can be found in [49].

In addition to the circulation patterns, several regional level monsoon indices are also considered in this study. The indices include the Indian Summer Monsoon Index (ISMI), Western North Pacific Monsoon Index (WNPMI), Webster and Yang Monsoon Index (WYMI), South Asian Summer Monsoon index (SASMI), and East Asian Summer Monsoon Index (EASMI). ISMI, WNPMI, and WYMI are accessible in [50] whereas SASMI and EASMI indices are found in [51]. 


\subsection{Study Methods}

\subsubsection{Trend Analysis}

This study used a nonparametric-based Mann-Kendall (MK) test to estimate the trends in climate change indices. The test compares relative magnitudes rather than the data values. The robustness of the MK test was highlighted in previous studies [52]. The MK test possesses several advantages such as being insensitive to outliers and missing data in time series. Estimated Z-scores are used to represent the magnitude of trends. The positive $Z$ value infers a positive trend and vice versa.

\subsubsection{Correlation Analysis}

Assessment of global teleconnections impact and regional monsoon indices with extreme precipitation indices is performed with the help of Spearman's correlation analysis. Spearman's correlation is estimated between two parameters with their variance and means $[31,32,53]$. The correlation measurements range from -1 to +1 . Correlation of +1 indicates a perfect linear equation that describes the relationship between two parameters, correspondingly, -1 indicates an opposite relationship between two parameters. A correlation of zero represents no linear relationship between two parameters.

\section{Results}

\subsection{Regional Characteristics of Climate Change Indices}

The spatiotemporal variability of monsoonal rainfall dramatically influences the economy and societal life of the MA region. Historically, many studies investigated the nature of MA rainfall variability and associated attributes such as aerosols, Eurasian ice, volcanic eruptions, and SST anomalies, etc. [54-57]. Although the nature of rainfall variability has been perturbed by all means with possible factors as mentioned, the signature is much pronounced at extreme sides rather than the mean variability of rainfall in recent decades [6]. This section further presents the spatial variability of precipitation in the light of extreme precipitation indices. The spatial variability of annual mean rainfall is complex in nature over MA as shown in Figure 1. Figure 2 illustrates the decadal mean spatial variability of climate change indices along with histograms. Histograms represent the bin-wise distribution of precipitation indices over MA. Histogram analysis gives information regarding the maximum occurrence of extreme precipitation climate change indices measurements on the regional level. The mean spatial variability of quantitative precipitation climate change indices such as $\mathrm{R} \times 1, \mathrm{R} \times 5, \mathrm{R} 95$, and SDII are presented in the left panel of Figure 2. The CDD, CWD, and R10 are shown in the right panel of Figure 2. Maximum one-day precipitation $(R \times 1)$ replicates similar spatial distribution to annual mean rainfall variability over MA (Figure 1). Wet regions such as the Western Ghats, the northeast in the Indian subcontinent, western coastal belts for the Myanmar region, central forest range in Papua New Guinea, a northwestern island of the Philippines, and some southern parts of Japan are observed to be hot spots for one-day extreme precipitation $(R \times 1)$ events.

The regions with a relatively large magnitude of one-day maximum precipitation $(\mathrm{R} \times 1)$ events mostly belong to coastal and rich topography regions. The intensity of $\mathrm{R} \times 1$ relatively seems to be higher over the regions that come under the influence of the orography effect, as concluded in previous studies [58,59]. Therefore, it is supposed that geographical features such as orography over wet regions in MA seem to play a significant role in enhancing the severity of maximum one-day precipitation $(R \times 1)$ and consequently lead to more flash floods $[52,60]$. 

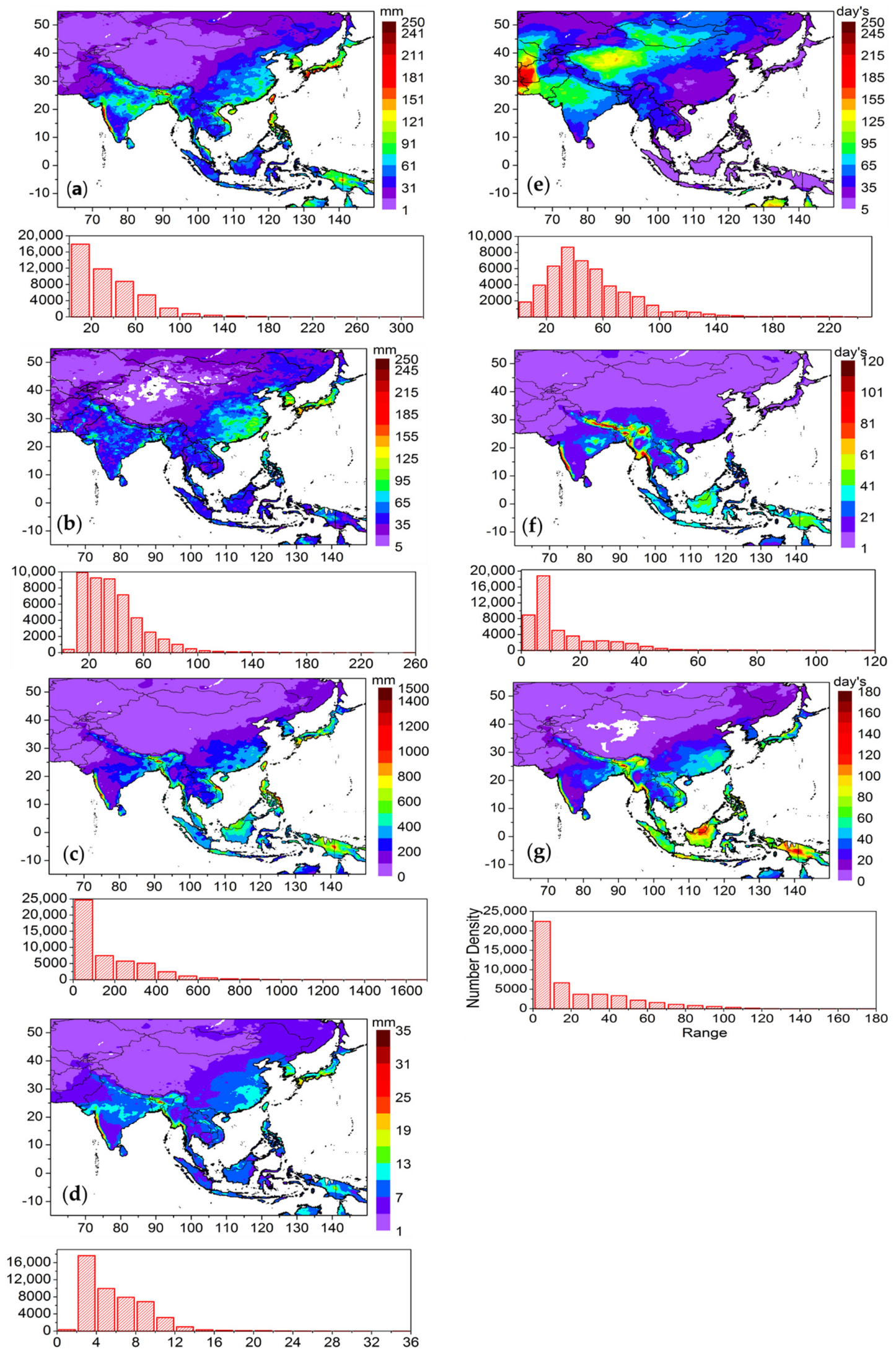

Figure 2. Annual mean spatial variability in precipitation climate change indices (a) $\mathrm{R} \times 1$ (mm), (b) $\mathrm{R} \times 5$ (mm), (c) $\mathrm{R} 95$ (mm), (d) SDII (mm/day), (e) CDD (days), (f) CWD (days), and (g) R10 (days) and corresponding histograms that represent bin-wise distribution of precipitation indices. 
It is possible that the annual mean rainfall is strongly associated with maximum oneday precipitation $(R \times 1)$ and the amount of precipitation form extremes (R95), especially over coastal regions such as the Western Ghats, India. The dual effect of maximum mean $\mathrm{R} \times 1$ and $\mathrm{R} 95$ measurements over coastal regions results in relatively higher mean values in SDII. Though central India depicts maximum values in $\mathrm{R} \times 1$, the lower SDII over central India is attributed to less precipitation contributed from extreme precipitation events (R95). Spatial variability of the 5-day maximum precipitation $(R \times 5)$ seems to be scattered over the Indian subcontinent and maritime continent. Rain-fed regions over China and Japan depict relatively higher 5-day precipitation. The dominant fraction of the study region shows SDII with magnitudes of $\sim 7-13 \mathrm{~mm}$ except coastal regions that are vulnerable to heavy precipitation with SDII index greater than $13 \mathrm{~mm}$. Such higher mean values in SDII over specific regions are contributed from $R \times 1, R 95, C W D$, and R10. Considering the diverse nature of geographical features in the MA region, the mean spatial variability of extreme precipitation climate change indices reflected the contrasting characteristics of annual mean rainfall over MA. For instance, $\mathrm{R} \times 1$, R95, and R10 replicate similar distributions to annual mean rainfall variability. Such a significant correlation between precipitation climate change indices and annual mean rainfall is also observed in earlier studies $[19,58]$.

Climate change indices such as CDD show dry days with a longer interval (about 3 to 6 months) over rain deficient and desert regions such as the north Asian region. It is noteworthy to mention that the histogram of CDD shows the maximum number of grids having 30-40 days as a dry period, which resembles the MJO seasonal cycle. Similarly, the histogram of CWD depicts a maximum occurrence of CWD over 5-10 day intervals, which implies that the dominant nature of 5-7 days oscillations of summer monsoon rainfall over MA. The maximum mean values (about 2-3 months) of CWD are observed over topography-rich regions and exposure to mass air movements. It is interesting to note that the regions that show maximum/minimum CDD/CWD or vice versa are not the same. The spatial variability of the number of precipitation events with $10 \mathrm{~mm}$ (R10) rainfall quietly replicates the spatial variability of annual mean rainfall. Frequent intensive convective activities result in the maximum number of R10 precipitation events over the maritime continental region. Moreover, recent simulations carried out over the maritime continent suggest an amplified projection in precipitation climate change indices over the maritime continent [61].

Nevertheless, China and Japan present higher SDII values with low CDD and CWD implies a smaller number of wet days with higher annual rainfall. Yu et al. (2020) [20] also concluded the similar increasing trends in SDII over the China region. Although various MA sub-regions experienced contrasting trends in precipitation climate change indices, $\mathrm{R} \times 1, \mathrm{R} 95$, and SDII share common sub-regions with similar tendencies.

The spatial variability in annual mean precipitation and extreme precipitation climate change indices inferred spatial heterogeneity in the mean and extreme precipitation distribution over the MA region, as observed in Figures 1 and 2. Further understanding of the trends in precipitation climate change indices reveals possible changes in precipitation patterns due to recent intensified climate change over different regions for the past two decades in MA.

Figure 3 narrates recent decadal trends in precipitation climate change indices over the MA. Semi-arid regions such as the southeast and northwest and central India show an increasing trend in $\mathrm{R} \times 1$. The wettest region (Western Ghats of India) depicts a decreasing trend in $\mathrm{R} \times 1$ over some isolated grids. Equatorial tropical countries within the maritime continent show intensified daily maximum one-day precipitation $(R \times 1)$. The annual maximum 5-day continuous precipitation does not furnish a clear indication in trends over MA. Precipitation contributions from extremes (R95) and conditional annual mean precipitation (SDII) show similar spatial patterns in recent trends. The major discrepancy is that China's monsoonal wet regions observed an increasing trend in precipitation amount 
contributed from extremes (R95). Overall, the maximum number of grids shows an increasing trend in $\mathrm{R} \times 1$ and $\mathrm{R} 95$ over MA.
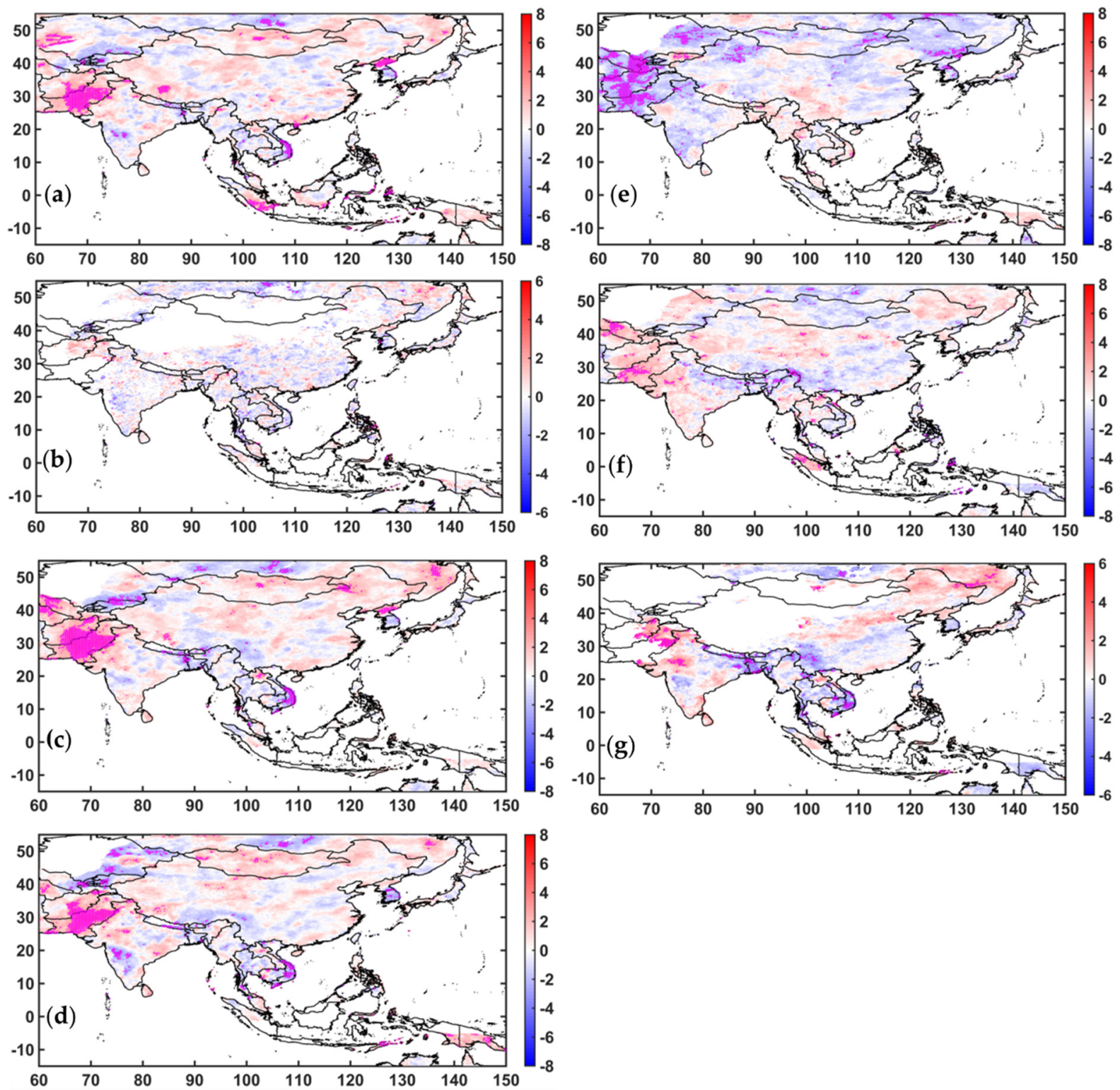

Figure 3. Spatial patterns of trends in extreme precipitation climate change indices over monsoon Asia during 1998-2015. Where (a) R × 1, (b) R × 5, (c) R95, (d) SDII (e) CDD, (f) CWD, and (g) R10. The significant trends are shown with magenta colored squares.

The number of consecutive dry days (CDD) exhibits a declining trend dominantly over southern MA countries. The Indian subcontinent also shows a change in CDD towards a decreasing trend in magnitude. The arid regions such as Pakistan, Afghanistan, Thar, and the Gobi Desert depict a decline in a long dry spell. Duration of continuous rainfall (CWD) is prolonged over Western Ghats, India, and the maritime continental region except for Papua New Guinea. SAARC countries such as Bangladesh, Nepal, and some parts of Myanmar, Thailand, and Vietnam recorded declining trends in CWD in recent decades. The spatial distribution of trends in the number of events with $10 \mathrm{~mm}$ (R10) precipitation is quite analogous to CWD for the MA region, excluding WG, India, Pakistan, and Afghanistan, where CWD does not show significant trends.

Although various MA sub-regions experienced contrasting trends in precipitation climate change indices, $\mathrm{R} \times 1$, R95, and SDII share common sub-regions with similar ten- 
dencies. Though the intensity of precipitation extremes $(\mathrm{R} \times 1$, R95) shows an increasing trend over MA sub-regions, the duration (CWD) and frequency (R10) of extremes are relatively larger over continental countries. Previous literature also highlighted similar trends over tropical countries $[16,26]$. The decreasing trends in CDD reported over arid regions such as the Gobi Desert and Pakistan, Afghanistan and northwest India are attributed to increasing precipitation activity due to global warming [62]. Similarly, countries located around the head Bay of Bengal in the South-East region resemble similar decreasing trends dominantly in $\mathrm{R} \times 1, \mathrm{R} 95, \mathrm{CWD}$, and R10. Interestingly, such decreasing trends in relative wet indices indicate a drying signal over such regions. Delayed and changing distribution patterns of precipitation over such regions are major factors for observed drought conditions [63].

The regional trends in climate change indices indicate contrasting features in the past two decades over the MA region. Maritime continental countries exhibit comparatively similar trends in climate change indices such as R95, R10, and SDII whereas large landmasses such as India, China, and adjacent countries depicted similar trends in R95. Though the spatial distribution in trends implies possible changes in regional scale extreme precipitation indices, common and distinct features in trends on a regional scale, the areal mean tendencies in climate change indices further could account for the vulnerability of the MA region to extreme precipitation variability in terms of different precipitation climate change indices. The areal average trends in extreme precipitation climate change indices are shown in Figure 4. Extreme precipitation-based indices such as $R \times 1$ and R95 set an increasing tendency with slopes of $0.3 \mathrm{~mm}$ and $0.5 \mathrm{~mm}$ per year during the past two decades. Consecutive dry days (CDD) and the number of rainy days greater than $10 \mathrm{~mm}$ (R10) present a decreasing tendency during the study period (1998-2015). Though the increase in CWD is seen over the MA region, the slope is relatively less compared to CDD.
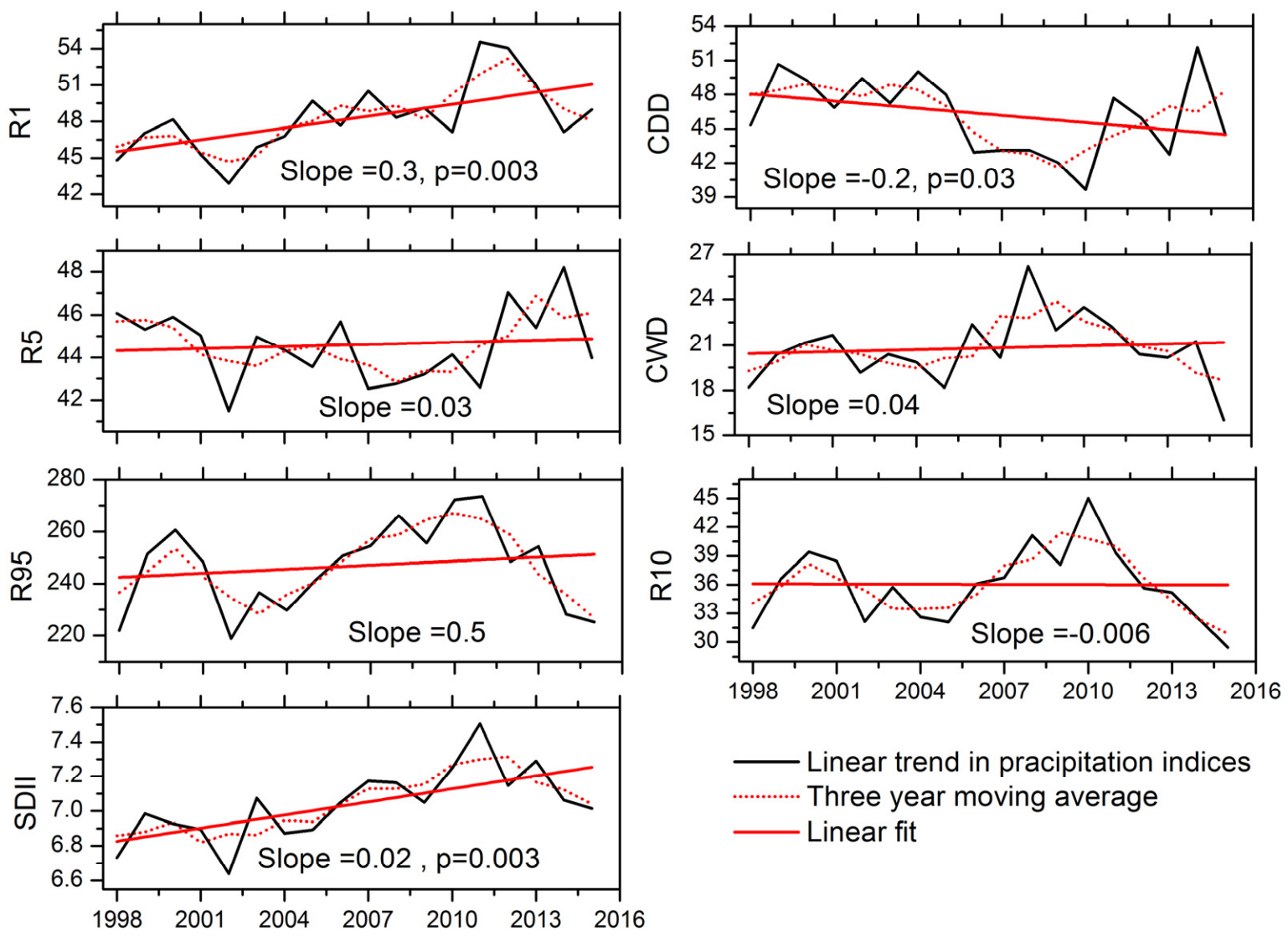

Figure 4. Area averaged time series in extreme precipitation climate change indices. The black line indicates the area average time series of climate change indices. Dotted and solid red lines represent a three-year running average and linear fit in climate change indices. The significant trends are shown with corresponding $p$-values. 
Based on regional average trends, extreme precipitation indices elucidate increasing trends during the last couple of decades. The ETCCDI defined precipitation climate change indices are largely associated with each other. For example, the increase in CWD can influence the SDII index over a region. Therefore, Table 2 illustrates the mutual correlation between precipitation climate change indices to further account for how observed variation in each climate change index is got reflected in other indices' variability. The negative correlation of the CDD index with all other indices is attributable to an opposite trend in both indices. Though such a contrasting signature is detected until 2010, CDD shows a similar trend to other indices later 2010 (Figure 4). Thus, it may be concluded that the duration of the rainfall active spell has been decreasing later than 2010. The increase in R95 and decrease in CWD indicate extreme precipitation events of a short duration nature. Precipitation contributed from extremes (R95) depicts a significant correlation with the maximum number of other indices. The highest correlation is reflected between the number of rainy days greater than $10 \mathrm{~mm}$ (R10) and R95. R10 and SDII also follow similar variations as other indices with correlation magnitudes exceeding 0.5 . $R \times 1$ is exempted from such a large association with other indices and exhibits a reasonable correlation with R95 and SDII.

Table 2. Mutual correlation coefficients between precipitation climate change indices. ${ }^{*}$ is 0.05 significance, and ${ }^{* *}$ is the 0.01 significance level.

\begin{tabular}{cccccccc}
\hline & CDD & CWD & $\mathbf{R} \times \mathbf{1}$ & $\mathbf{R} 10$ & $\mathbf{R} \times \mathbf{5}$ & $\mathbf{R 9 5}$ & SDII \\
\hline CDD & 1 & & & & & & \\
CWD & -0.3 & 1 & & & & & \\
R $\times 1$ & -0.22 & 0.1 & 1 & & & & \\
R10 & $-0.44^{*}$ & $0.83^{* *}$ & 0.18 & 1 & & & \\
R $\times 5$ & 0.26 & -0.07 & 0.006 & -0.16 & 1 & & \\
R95 & $-0.45^{*}$ & $0.72^{* *}$ & $0.54^{* *}$ & $0.89^{* *}$ & -0.18 & 1 & \\
SDII & -0.4 & $0.46^{*}$ & $0.76^{* *}$ & $0.53^{*}$ & -0.03 & $0.74^{* *}$ & 1 \\
\hline
\end{tabular}

\subsection{Teleconnections of Climate Change Indices with Temperature and Total Column Water Vapor}

Spatial variability of climate change indices and temporal trends imply contrasting features concerning different regions, notably tropical to subtropical regions over MA (Figures 2 and 3). The manifestation of such variability in climate change indices, even in mean rainfall, is primarily associated with changes in mean $\mathrm{T}\left({ }^{\circ} \mathrm{C}\right)$ measurements and the availability of TCW $(\mathrm{g} / \mathrm{kg})$ in the atmosphere [64]. Both the parameters interact with each other and have a significant attribution to changes in precipitation patterns. Numerous reports highlighted how regional and large-scale changes in T and TCW could influence the nature of rainfall systems from sub-daily scale to seasonal scale [65]. Figure 5 shows the meridional mean variability of climate change indices overland against $\mathrm{T}$ and TCW variability. When comparing the significant influence of T and TCW on precipitation climate change indices, TCW availability in the atmosphere seems to be a crucial attributor for the variability of climate change indices. Maximum one-day precipitation, $\mathrm{R} \times 1$ follows a similar variability, as seen in the case of $\mathrm{T}$. The gradual decline in $\mathrm{T}$ later $25^{\circ} \mathrm{N}$ may be attributed to the Himalayan region's cold surface conditions. The maximum one-day precipitation $(R \times 1)$ and SDII show similar variability to T up to $30^{\circ} \mathrm{N}$. Though the temperatures measurements are increased later to $30^{\circ} \mathrm{N}$, the lack of enough moisture availability later $30^{\circ} \mathrm{N}$, and arid conditions (Figure 1) over central Asia may be responsible for a decrease in mean extreme precipitation measurements over MA. The peak values in $\mathrm{R} \times 1, \mathrm{SDII}$, and $\mathrm{T}$ around $15-25^{\circ} \mathrm{N}$ signify the role of surface temperature conditions on $\mathrm{R} \times 1$, the maximum occurrence of $\mathrm{R} \times 1$, and fractional contribution of $\mathrm{R} \times 1$ to SDII. Excluding $\mathrm{R} \times 1$ and SDII, the other indices reflect a similar variability, as observed in TCW. R95, CDD, CWD, and R10 mm climate change indices are closely associated with TCW variability. 

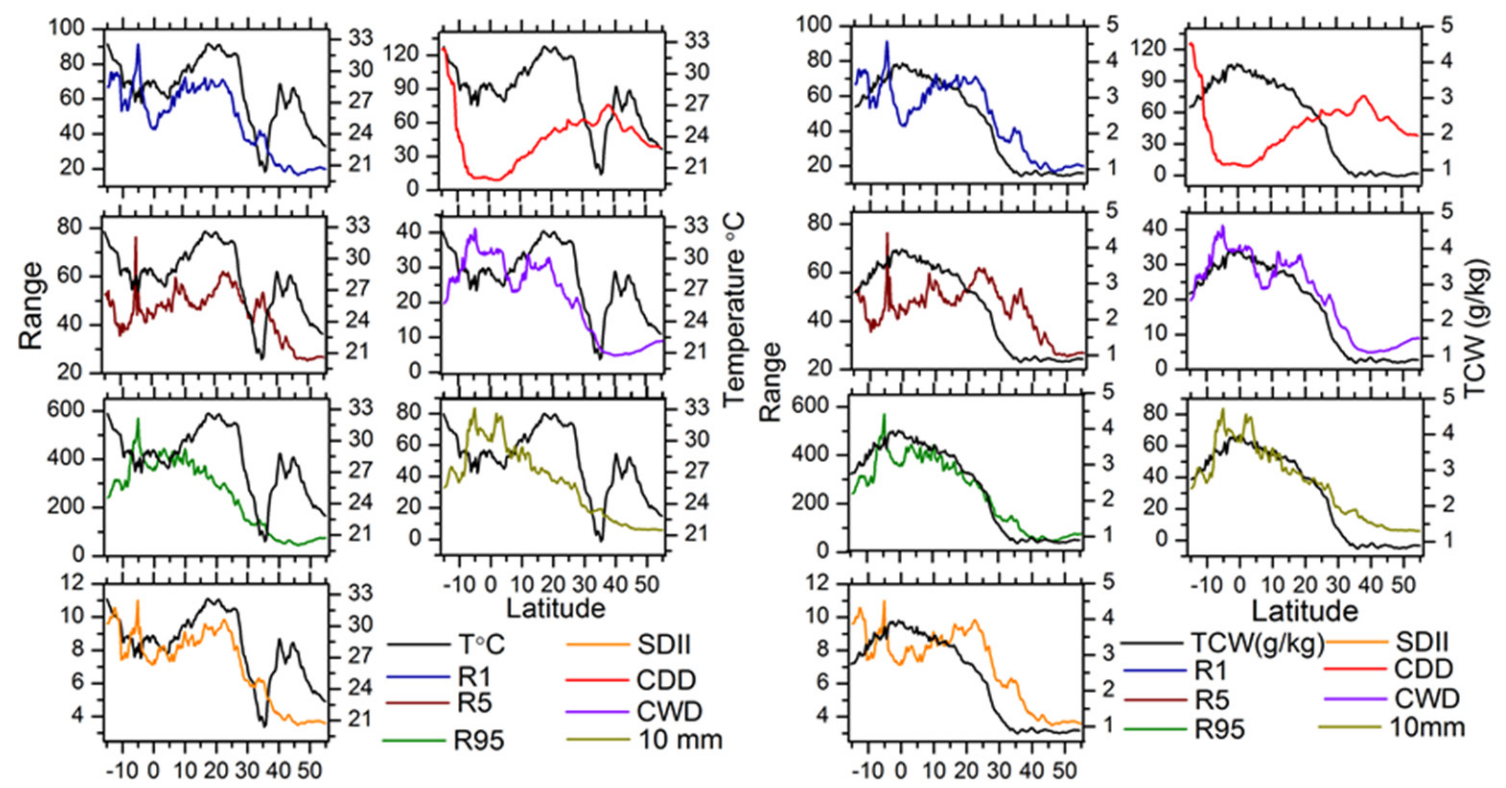

Figure 5. The variation in extreme precipitation climate change indices and surface temperature $\left(\mathrm{T}^{\circ} \mathrm{C}\right)$ and $\mathrm{TCW}(\mathrm{g} / \mathrm{kg})$ over MA. For each sub-figure, the left Y-axis scale represents the scale for precipitation climate change indices and the right Y-axis scale represents the scale for T and TCW.

For example, the opposite nature in variability, increasing/decreasing in mean values of $\mathrm{CDD}$ and TCW around $10^{\circ} \mathrm{N}$ which implies the length of CDD is negatively influenced by the availability of TCW. A similar variability of R95, CWD, SDII, and R10 is also observed with maximum correlation R95 with other indices as shown in Table 2. The predominant influence of TCW on quantitative indices such as CDD, CWD, and R10 mm leaves a riddle for future scope. The relative availability of TCW in the atmosphere and surface temperature $\left(\mathrm{T}^{\circ} \mathrm{C}\right)$ depicts an apparent intra-annual variability throughout the year (Figure 6). In general, the summer months (JJAS) exhibit a maximum peak in mean precipitation. Though such intra-annual variability drastically varies over different climate zones over the study period, the comparative analysis of inter-annual variability of climate change indices with TCW and T further depicts the connectivity of TCW, T with climate change indices on a monthly scale as demonstrated in Figure 6.

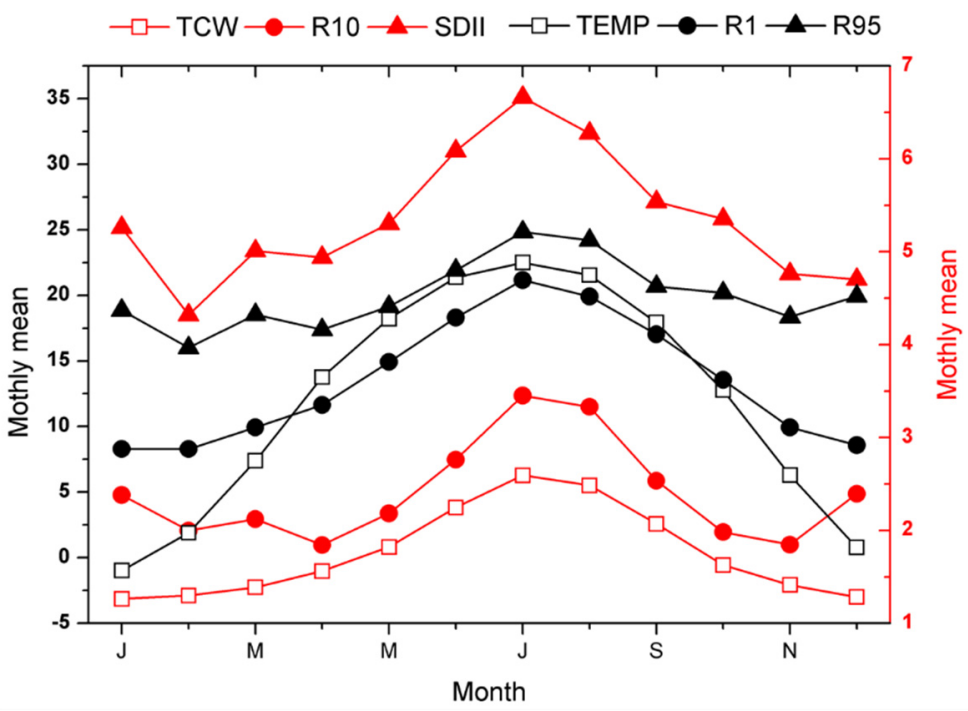

Figure 6. Monthly variation in precipitation climate change indices, surface temperature $\left(\mathrm{T}^{\circ} \mathrm{C}\right)$, and total column water vapor (TCW g/KG). The black/red colored time series referred to the left/right Y-axis scales. 
The monthly variation in TCW is reflected in various climate change indices such as R95, SDII, and R10, as maximum TCW values are observed in the wet season (JJAS) in Figure 6. The surface temperature depicts a smooth transition from one month to next month, and similar variability is also observed in R1. However, total water vapor does not show any significant transition like temperature. For example, the increases in mean values of TCW from Dec to Jan are clearly reflected in an increase in SDII, R95, and R10. Such type of variability is also depicted in Figure 5.

Comparing latitudinal variability of TCW and T with precipitation climate change indices highlighted the possible quantitative linkages between climate change indices variability and TCW, T. Excluding $\mathrm{R} \times 1$ and SDII, other climate change indices such R95, CDD, CWD, and R10 are closely associated with TCW variability. Such a strong association of climate change indices with TCW was also found in [66]. Though $\mathrm{R} \times 1$ possesses similar variability to $\mathrm{T}$, the mutual association seems to be weakened over latitudes greater than $35^{\circ}$ north.

\subsection{Global Teleconnections and Climate Change Indices}

MA region receives a maximum fraction of annual rainfall from gigantic circulation patterns due to seasonal oscillation of the Inter-Tropical Convergence Zone (ITCZ). It is well established that such monsoon circulation systems are often remotely influenced by the state of the many global teleconnections such as AMO, PDO, SOI, NAO, and MJO. The relative attribution to spatiotemporal rainfall variability by such global teleconnections could be a contrast in nature. Several large-scale circulation patterns and regional level monsoon indices possibly linked to monsoon rainfall variability over MA are considered to reveal the nature of synoptical scale forcing on variability of climate change indices.

The source of the rainfall-bearing systems over the MA region is associated with the global mean wind circulation patterns, sea surface temperature variation, and land surface conditions. However, the local geographical features such as orography and water bodies can modify the dynamical and thermos-dynamical effects of rainfall source mechanisms over selected regions such as the Western Ghats in MA.

To examine the possible influence of global teleconnections on decadal variability of extreme precipitation climate change indices the correlation analysis between climate change indices and global teleconnections, regional monsoon indices are considered. A total number of 18 various global and regional scale winds, seas surface temperature, and land temperature-based teleconnections are linearly correlated with climate change indices. However, we have only included teleconnections and regional monsoon indices with a minimum correlation of 0.4 in Table 3. Further, the spatial correlation maps are also shown in Figure S1, which shows positive correlation-region pairs with SOI, such as India CWD, southern China region-CDD, Malaysia region-R95, and negative over desert regions of $\mathrm{MA}$.

Among various teleconnections and monsoon indices, the SST conditions over the equatorial Pacific Ocean are strongly correlated with the temporal variability of climate change indices through ENSO-related indices such as SOI, MEI V2, and Nino 3.4 measures. Four out of seven climate change indices (CWD, R10, R95, and SDII) are significantly correlated with SOI. Though the correlation is computed with a lag period, such significant correlations between climate change indices and SOI were also observed in southeastern countries [29]. Indices such as R10 and R95 set a relatively significant correlation with the SOI index (Figure 7). The highest correlation of SOI with R95 indicates the dominant role of SST conditions over the western Pacific for supplying abundant moisture supply over MA.

Such significant features are also observed with other ENSO-related indices such as Nino 3.4, with significant negative correlation magnitudes with CWD, R10, and R95. Other ENSO-related indices such as MEI V2 also imply an apparent negative correlation with all the climate change indices except CDD. As the increase in MEI V2 values signifies strong El-Niño conditions, the magnitude of climate change indices is expected to decline, which is apparent from the negative correlations observed with MEI V2. The significant differences 
in pressure anomalies during different SST conditions over the equatorial Pacific influence the circulation patterns, such as Hadley and Walker cells over MA. The normal/La-Nina conditions favor warmer SST over the western Pacific and influence surface temperature conditions over MA. Moreover, the lower-level anticyclone flow, upper-level cyclonic flow, and west-east gradients in updrafts also favor large-scale convection over MA. The increase in observed global mean temperature that enhances water vapor holding capacity in the atmosphere and the strong southwesterly flow due to low-level anticyclone west Pacific along with favorable surface temperature conditions cause extreme precipitation events over MA. However, annual maximum daily precipitation $\mathrm{R} \times 1$ depicts a relatively stronger positive correlation with DMI. IOD seems to be a relatively valid attributor than the ENSO for annual $\mathrm{R} \times 1$.

Table 3. Spearman correlation coefficients between precipitation climate change indices and various global teleconnection indices and regional level monsoon indices over monsoon Asia. * is the 0.05 significance level, and ${ }^{* *}$ is the 0.01 significance level. DMI-Dipole Mode Index, EMI-El-Niño Modoki Index, Nino 3.4-East-Central Tropical Pacific SST, PDO—Pacific Decadal Oscillation, SOISouthern Oscillation Index, MEI V2-Multivariate ENSO Index, NAO-North Atlantic Oscillation, MJO-Madden and Julian Oscillation (MJO), WYMI-Webster and Yang Monsoon Index, and EASMI-East Asian Summer Monsoon Index.

\begin{tabular}{cccccccc}
\hline & CDD & CWD & $\mathbf{R} \times \mathbf{1}$ & $\mathbf{R 1 0}$ & $\mathbf{R} \times \mathbf{5}$ & $\mathbf{R 9 5}$ & SDII \\
\hline DMI & -0.18 & 0.22 & 0.37 & 0.28 & -0.18 & 0.25 & 0.33 \\
EASMI & $0.45^{*}$ & -0.11 & -0.09 & -0.19 & 0.04 & -0.28 & $-0.46^{*}$ \\
EMI & 0.18 & -0.44 & -0.11 & $-0.51^{*}$ & -0.32 & $-0.52^{*}$ & -0.20 \\
GMLOT & -0.32 & -0.29 & 0.23 & $-0.47^{*}$ & -0.05 & -0.27 & 0.17 \\
MEV2 & 0.10 & $-0.58^{*}$ & -0.44 & $-0.80^{* *}$ & -0.01 & $-0.87^{* *}$ & $-0.59^{* *}$ \\
MJO_AMP & 0.14 & -0.18 & -0.09 & -0.24 & $-0.49^{*}$ & -0.33 & -0.43 \\
NAO & $0.45^{*}$ & -0.29 & 0.10 & -0.15 & -0.04 & -0.06 & -0.02 \\
NINO 3.4 & 0.02 & $-0.38^{*}$ & -0.28 & $-0.68^{* *}$ & -0.14 & $-0.72^{* *}$ & -0.40 \\
PDO & 0.19 & $-0.48^{*}$ & -0.37 & $-0.69^{* *}$ & 0.01 & $-0.75^{* *}$ & $-0.46^{*}$ \\
SOI & -0.32 & $0.65^{* *}$ & 0.37 & $0.86^{* *}$ & -0.09 & $0.91^{* *}$ & $0.62^{* *}$ \\
WYMI & 0.44 & -0.19 & -0.43 & 0.04 & 0.14 & -0.08 & $-0.55^{* *}$ \\
\hline
\end{tabular}

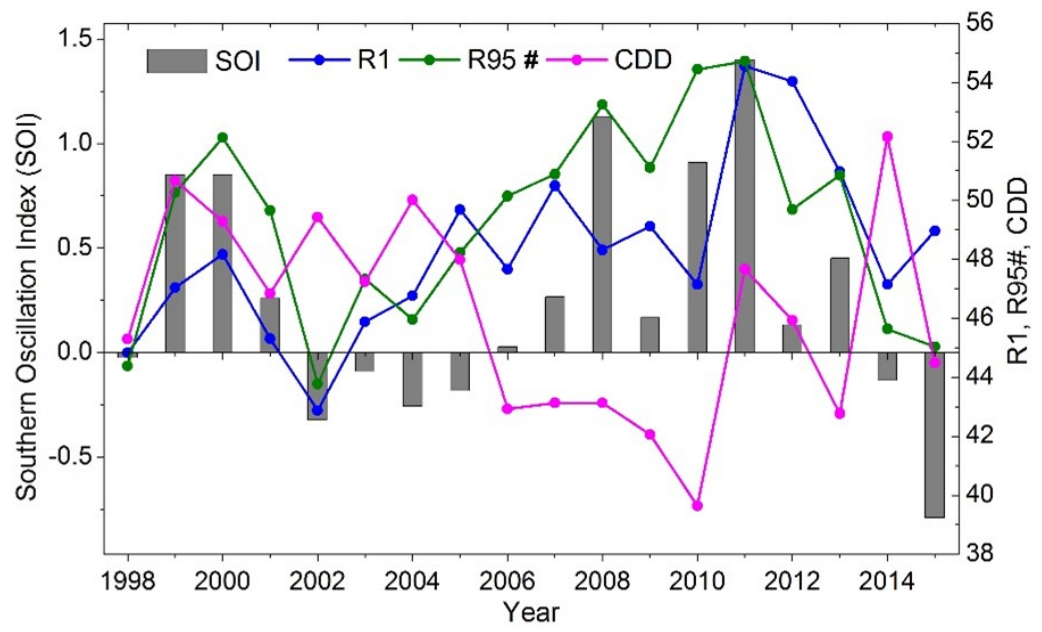

Figure 7. The Southern Oscillation Index (SOI) influences $\mathrm{R} \times 1, \mathrm{R} 95$, and CDD over the study region. Note: actual R95 is normalized as R95\#= $(\mathrm{R} 95 / 10) * 2$.

Earlier literature infers that the positive phase of IOD increases convective available potential energy over MA, which in turn often causes local convections. In addition to the remote influence of equatorial SST, the decadal oscillations of climatology SST over the Pacific Ocean (PDO) also show a strong association with precipitation climate change indices (R10, CWD, and R95) over MA. Similarly, consecutive dry days (CDD and R10 perform a comparatively positive/negative correlation with NAO). Several earlier 
studies support such significant climate impact of NAO and PDO on the spatial pattern of precipitation in the South-east monsoon region and sub-regions in MA [67-69]. Though the period of PDO is longer than ENSO, the cold/warm phase of PDO can alter the influence of the ENSO on climate over MA. Since the cold phase of PDO indicates an increase in climatologically mean SST over the eastern Pacific, it may shift the circulation pattern towards the eastern Pacific. As such, the shift does not favor a good monsoon over MA, PDO exhibits a negative correlation with CDD, R95, and R10. Though the impact of NAO on MA climate is not clear, the NAO is the chief source of connecting bridge for wave trains generated over North Atlantic and across Pacific and ends at east Pacific by Rossby waves.

One possible attributor may be that during El-Niño conditions, the impact of NAO may intensify and can cause dryness over MA. Both AO and AMO depict a weak correlation with precipitation climate change indices. The weakening of meridional gradient in tropospheric temperature is a possible factor for the observed weak correlation of AMO and precipitation indices. Considering MJO amplitude and the first two principal components (RMM1 and RMM2), the second component MJO RMM2 shows similar inter-annual variability like $\mathrm{R} \times 1$. The dominant Indian Ocean phenomenon of sea surface temperature contrast (DMI) also appears reasonably to influence the maximum one-day precipitation $(R \times 1)$ over the study region. The regional level monsoon indices such as EASMI, EMI, ISMI, SASMI, WNPMI, and WYMI are poorly associated with climate change indices except for CDD, which shows a valid correlation (0.5) with the EASMI monsoon index.

\section{Summary and Conclusions}

The present study analyzed the recently available improved version of APHRODITE precipitation (APHRO_V1901) and temperature (APHRO_V1808) datasets to evaluate the recently observed trends in precipitation climate change indices. The trends are represented by several precipitation amounts based climate change indices (annual daily maximum one-day precipitation $(R \times 1)$, annual maximum consecutive five-day precipitation $(R \times 5)$, annual precipitation contributed from 95 percentile (R95), and Simple Daily Intensity Index (SDII) and quantity-based climate change indices (consecutive dry days (CDD), consecutive wet days (CWD), and the number of rainy days greater than $10 \mathrm{~mm}$ (R10). The observed spatial variability and trends in climate change indices are discussed with different geographical features and precipitation regimes over the study region. The influence of large-scale circulation patterns on precipitation climate change indices is investigated and explored the possible influence of large-scale circulation patterns on precipitation climate change indices over MA. The possible role of spatial variability of total column water vapor and surface temperature on precipitation climate change indices are revealed over MA. The present study has some limitations such as simple statistical approaches like correlation coefficient is used to evaluate the link between large-scale connection and precipitation climate change indices. Advanced statistical tools such as Principal Component Analysis (PCA) or Empirical Orthogonal Functions (EOF) may provide more insights into the connection between extreme climate change indices and large-scale teleconnections. Another drawback from the current analysis is the validity of observed trends in recent decades. The observed trends are not applicable to long-term climate change. The major findings from the present study are as follows:

1. The mean spatial variability of precipitation climate change indices reflected the contrasting characteristics of annual mean rainfall over MA. The intense nature of maximum one-day precipitation $(\mathrm{R} \times 1)$ events and precipitation contributed from extremes, R95 dominantly shows a higher annual mean over coastal regions in MA. Countries within the maritime continent show the maximum number of precipitation events with a magnitude greater than $10 \mathrm{~mm}$ (R10).

2. Decreasing trends in CDD are reported over arid regions such as the Gobi Desert and Pakistan, Afghanistan, and northwest India. A similar resemblance of decreasing trends in $\mathrm{R} \times 1, \mathrm{R} 95, \mathrm{CWD}$, and R10 are observed in countries located around the head Bay of Bengal in the Southeast region. The wet indices $(R \times 1, R 95$, and CWD) 
with observed decreasing trends indicate a drying signal over such regions. On the contrary, the number of consecutive dry days depicts a declining trend over arid regions such as the Gobi Desert, Pakistan, and Afghanistan, which may indicate enhancement in precipitation activity over such regions.

3. On comparing areal average tendency in trends, it is observed that recent trends in $\mathrm{R} \times 1$ and $\mathrm{R} 95$ set an increasing tendency with slopes of $0.3 \mathrm{~mm} / \mathrm{yr}$ and $0.5 \mathrm{~mm} / \mathrm{yr}$. Such positive trending nature in wet indices over coastal regions may impact the frequency the floods over coastal regions.

4. The decadal co-variability of extreme precipitation climate change indices is relatively reflected in R95 when compared with other indices. The availability of total column water vapor over different latitudes is closely associated with variability of R95, SDII, and R10 climate change indices, whereas surface temperature seems to play a key role in maximum one-day extreme precipitation $(R \times 1)$ variability.

5. The prevailing conditions of the SST over the equatorial Pacific Ocean are strongly correlated with the variability of extreme precipitation climate change indices through relative phases of SOI, MEI V2, and Nino 3.4 indices. Extreme precipitation indices such as R95, SDII, CWD, and R10 are strongly correlated with ENSO indices. The combined effect of ENSO and PDO can influence the extreme precipitation variability over MA.

To understand and further extend the potential application of precipitation climate change indices, precipitation climate change indices can be accessed to evaluate the link between floods, droughts, and climate change indices. With the observed results and earlier literature, large-scale circulation patterns certainly have remarkable associations with precipitation climate change indices trends. Further quantification of the large-scale circulation pattern's influence on climate change indices becomes difficult due to the intricate interaction between large-scale circulation patterns and precipitation variability. For example, the combined influence of the ENSO and PDO with different individual phases certainly improves our understanding of the impact of global warming on MA extreme precipitation events through modulation in circulation patterns. The interaction of large-scale circulation patterns is not limited to individual attribution but also a mutual interplay. Thus, further detailed investigation of large-scale circulation patterns with climate change indices from an adequate ensemble perception would provide more insights. A modeling framework and an extended study are required to know the feedback mechanism between remote influences on these indices of precipitation. Though the variability of TCW and T with climate change indices is objectively presented, the regional level assessment with in-depth details may further offer a significant TCW and T role on climate change indices variability.

Supplementary Materials: The following are available online at https:/ / www.mdpi.com/article / 10.3390/atmos12111492/s1, Figure S1: Spatial patterns of Spearman correlation coefficients with Southern Oscillation Index Where (a) R × 1, (b) R95, (c) CDD, and (d) CWD.

Author Contributions: Conceptualization, S.K. and V.K.; methodology, S.K.; software, S.K. and V.K.; validation, P.K.P.; formal analysis and editing, S.K.; investigation, S.K.; resources, S.K.; data curation, S.K.; writing —original draft preparation, S.K.; writing—review and editing, S.K. and V.K.; visualization, S.K.; supervision, S.K.; project administration, S.K.; funding acquisition, V.K. All authors have read and agreed to the published version of the manuscript.

Funding: This research received no external funding.

Institutional Review Board Statement: Not applicable.

Informed Consent Statement: Not applicable.

Data Availability Statement: All the datasets are acquired from public resources and available online.

Acknowledgments: The authors are grateful to the APHRODITE and MAIAC product developers. The authors are also thankful to the online websites for providing and various datasets and making them available to use in the present study. 
Conflicts of Interest: The authors declare no conflict of interest.

\section{References}

1. Staudinger, M.D.; Grimm, N.B.; Staudt, A.; Carter, S.L.; Stuart, F.S., III; Kareiva, P.; Ruckelshaus, M.; Stein, B.A. Impacts of Climate Change on Biodiversity, Ecosystems, and Ecosystem Services: Technical Input to the 2013 National Climate Assessment; U.S. Global Change Research Program: Washington, DC, USA, 2012.

2. Krishnan, R.; Sanjay, J.; Gnanaseelan, C.; Mujumdar, M.; Kulkarni, A.; Chakraborty, S. Assessment of Climate Change over the Indian Region: A Report of the Ministry of Earth Sciences (MOES), Government of India; Springer Nature: Basingstoke, UK, 2020 ; p. 226.

3. Kharin, V.V.; Zwiers, F.W.; Zhang, X.; Hegerl, G.C. Changes in temperature and precipitation extremes in the IPCC ensemble of global coupled model simulations. J. Clim. 2007, 20, 1419-1444. [CrossRef]

4. Kumar, V.; Pradhan, P.K.; Sinha, T.; Rao, S.V.B.; Chang, H.-P. Interaction of a Low-Pressure System, an Offshore Trough, and Mid-Tropospheric Dry Air Intrusion: The Kerala Flood of August 2018. Atmosphere 2020, 11, 740. [CrossRef]

5. Ratnam, J.; Behera, S.; Ratna, S.; Rajeevan, M.; Yagamata, T. Anatomy of Indian heatwaves. Sci. Rep. 2016, 6, 24395. [CrossRef]

6. Yang, Y.; Gan, T.Y.; Tan, X. Spatiotemporal changes in precipitation extremes over Canada and their teleconnections to large-scale climate patterns. J. Hydrometeorol. 2019, 20, 275-296. [CrossRef]

7. Managing the Risks of Extreme Events and Disasters to Advance Climate Change Adaptation; Field, C.B., Barros, V., Stocker, T.F., Dahe, Q., Eds.; Cambridge University Press: Cambridge, UK, 2012; ISBN 9781139177245.

8. Sánchez-Benítez, A.; García-Herrera, R.; Vicente-Serrano, S.M. Revisiting precipitation variability, trends and drivers in the Canary Islands. Int. J. Climatol. 2017, 37, 3565-3576. [CrossRef]

9. Zhu, Z.; Li, T. A new paradigm for continental U.S. summer rainfall variability: Asia-North America teleconnection. J. Clim. 2016, 29, 7313-7327. [CrossRef]

10. Zhou, X.; Huang, G.; Wang, X.; Cheng, G. Future Changes in Precipitation Extremes Over Canada: Driving Factors and Inherent Mechanism. J. Geophys. Res. Atmos. 2018, 123, 5783-5803. [CrossRef]

11. Gao, L.; Huang, J.; Chen, X.; Chen, Y.; Liu, M. Contributions of natural climate changes and human activities to the trend of extreme precipitation. Atmos. Res. 2018, 205, 60-69. [CrossRef]

12. ETCCDI Precipitaion Climate Change Indices. Available online: http:/ / etccdi.pacificclimate.org/list_27_indices.shtml (accessed on 8 November 2021).

13. Alexander, L.V.; Arblaster, J.M. Assessing trends in observed and modelled climate extremes over Australia in relation to future projections. Int. J. Climatol. 2009, 29, 417-435. [CrossRef]

14. Donat, M.G.; Lowry, A.L.; Alexander, L.V.; O'Gorman, P.A.; Maher, N. More extreme precipitation in the world's dry and wet regions. Nat. Clim. Chang. 2016, 6, 508-513. [CrossRef]

15. Costa, R.L.; Macedo de Mello Baptista, G.; Gomes, H.B.; dos Santos Silva, F.D.; da Rocha Júnior, R.L.; de Araújo Salvador, M.; Herdies, D.L. Analysis of climate extremes indices over northeast Brazil from 1961 to 2014. Weather Clim. Extrem. 2020, $28,100254$. [CrossRef]

16. Singh, V.; Qin, X. Study of rainfall variabilities in Southeast Asia using long-term gridded rainfall and its substantiation through global climate indices. J. Hydrol. 2020, 585, 124320. [CrossRef]

17. Kim, I.-W.; Oh, J.; Woo, S.; Kripalani, R.H. Evaluation of precipitation extremes over the Asian domain: Observation and modelling studies. Clim. Dyn. 2019, 52, 1317-1342. [CrossRef]

18. Wang, X.; Hou, X.; Zhao, Y. Changes in consecutive dry/wet days and their relationships with local and remote climate drivers in the coastal area of China. Atmos. Res. 2021, 247, 105138. [CrossRef]

19. Gupta, V.; Jain, M.K.; Singh, P.K.; Singh, V. An assessment of global satellite-based precipitation datasets in capturing precipitation extremes: A comparison with observed precipitation dataset in India. Int. J. Climatol. 2020, 40, 3667-3688. [CrossRef]

20. Yu, Y.; Schneider, U.; Yang, S.; Becker, A.; Ren, Z. Evaluating the GPCC Full Data Daily Analysis Version 2018 through ETCCDI indices and comparison with station observations over mainland of China. Theor. Appl. Climatol. 2020, 142, 835-845. [CrossRef]

21. Kim, Y.H.; Min, S.K.; Zhang, X.; Sillmann, J.; Sandstad, M. Evaluation of the CMIP6 multi-model ensemble for climate extreme indices. Weather Clim. Extrem. 2020, 29, 100269. [CrossRef]

22. Kumar, S.; Chanda, K.; Pasupuleti, S. Spatiotemporal analysis of extreme indices derived from daily precipitation and temperature for climate change detection over India. Theor. Appl. Climatol. 2020, 140, 343-357. [CrossRef]

23. Zhang, M.; Chen, Y.; Shen, Y.; Li, B. Tracking climate change in Central Asia through temperature and precipitation extremes. J. Geogr. Sci. 2019, 29, 3-28. [CrossRef]

24. Yin, H.; Sun, Y. Characteristics of extreme temperature and precipitation in China in 2017 based on ETCCDI indices. Adv. Clim. Chang. Res. 2018, 9, 218-226. [CrossRef]

25. Dietzsch, F.; Andersson, A.; Ziese, M.; Schröder, M.; Raykova, K.; Schamm, K.; Becker, A. A global ETCCDI-based precipitation climatology from satellite and rain gauge measurements. Climate 2017, 5, 9. [CrossRef]

26. Panda, D.K.; Panigrahi, P.; Mohanty, S.; Mohanty, R.K.; Sethi, R.R. The 20th century transitions in basic and extreme monsoon rainfall indices in India: Comparison of the ETCCDI indices. Atmos. Res. 2016, 181, 220-235. [CrossRef]

27. National Centers for Environmental Information State of the Climate. Global Climate Report for annual 2019. 2019. Available online: https: / / www.ncdc.noaa.gov/sotc/global/201913 (accessed on 8 November 2021). 
28. Public Page for Heat and High Impact Weather. Available online: https://public.wmo.int/en/media/press-release/2019 -concludes-decade-of-exceptional-global-heat-and-high-impact-weather (accessed on 8 November 2021).

29. Loo, Y.Y.; Billa, L.; Singh, A. Effect of climate change on seasonal monsoon in Asia and its impact on the variability of monsoon rainfall in Southeast Asia. Geosci. Front. 2015, 6, 817-823. [CrossRef]

30. Wentz, F.J.; Ricciardulli, L.; Hilburn, K.; Mears, C. How much more rain will global warming bring? Science 2007, 317, 233-235. [CrossRef] [PubMed]

31. Sunilkumar, K.; Narayana Rao, T.; Saikranthi, K.; Purnachandra Rao, M. Comprehensive evaluation of multisatellite precipitation estimates over India using gridded rainfall data. J. Geophys. Res. Atmos. 2015, 120, 8987-9005. [CrossRef]

32. Sunilkumar, K.; Yatagai, A.; Masuda, M. Preliminary Evaluation of GPM-IMERG Rainfall Estimates Over Three Distinct Climate Zones With APHRODITE. Earth Sp. Sci. 2019, 6, 1321-1335. [CrossRef]

33. Fasullo, J. A mechanism for land-ocean contrasts in global monsoon trends in a warming climate. Clim. Dyn. 2012, 39, 1137-1147. [CrossRef]

34. Yatagai, A.; Kamiguchi, K.; Arakawa, O.; Hamada, A.; Yasutomi, N.; Kitoh, A. APHRODITE: Constructing a Long-Term Daily Gridded Precipitation Dataset for Asia Based on a Dense Network of Rain Gauges. Bull. Am. Meteorol. Soc. 2012, 93, 1401-1415. [CrossRef]

35. Ji, X.; Li, Y.; Luo, X.; He, D.; Guo, R.; Wang, J.; Bai, Y.; Yue, C.; Liu, C. Evaluation of bias correction methods for APHRODITE data to improve hydrologic simulation in a large Himalayan basin. Atmos. Res. 2020, 242, 104964. [CrossRef]

36. Andermann, C.; Bonnet, S.; Gloaguen, R. Evaluation of precipitation data sets along the Himalayan front. Geochem. Geophys. Geosystems 2011, 12. [CrossRef]

37. Yatagai, A.; Maeda, M.; Khadgarai, S.; Masuda, M.; Xie, P. End of the Day (EOD) Judgment for Daily Rain-Gauge Data. Atmosphere 2020, 11, 772. [CrossRef]

38. Aphrodite Data Download Page. Available online: http:/ / aphrodite.st.hirosaki-u.ac.jp/download/ (accessed on 8 November 2021).

39. Yasutomi, N.; Hamada, A.; Yatagai, A. Development of a Long-term Daily Gridded Temperature Dataset and Its Application to Rain/Snow Discrimination of Daily Precipitation. Glob. Environ. Res. 2011, 15, 165-172.

40. Vaquero-Martínez, J.; Antón, M.; Ortiz de Galisteo, J.P.; Cachorro, V.E.; Costa, M.J.; Román, R.; Bennouna, Y.S. Validation of MODIS integrated water vapor product against reference GPS data at the Iberian Peninsula. Int. J. Appl. Earth Obs. Geoinf. 2017, 63, 214-221. [CrossRef]

41. Bright, J.; Gueymard, C.; Killinger, S.; Lingfors, D.; Sun, X.; Wang, P.; Engerer, N. Climatic and Global Validation of Daily MODIS Precipitable Water Data at AERONET Sites for Clear-sky Irradiance Modelling. In Proceedings of the ISES EuroSun 2018 Conference: 12th International Conference on Solar Energy for Buildings and Industry, Rapperswil, Switzerland, 10-13 September 2018.

42. Shi, F.; Xin, J.; Yang, L.; Cong, Z.; Liu, R.; Ma, Y.; Wang, Y.; Lu, X.; Zhao, L. The first validation of the precipitable water vapor of multisensor satellites over the typical regions in China. Remote Sens. Environ. 2018, 206, 107-122. [CrossRef]

43. Martins, V.S.; Lyapustin, A.; Wang, Y.; Giles, D.M.; Smirnov, A.; Slutsker, I.; Korkin, S. Global validation of columnar water vapor derived from EOS MODIS-MAIAC algorithm against the ground-based AERONET observations. Atmos. Res. 2019, 225, 181-192 [CrossRef]

44. Lyapustin, A.; Alexander, M.J.; Ott, L.; Molod, A.; Holben, B.; Susskind, J.; Wang, Y. Observation of mountain lee waves with MODIS NIR column water vapor. Geophys. Res. Lett. 2014, 41, 710-716. [CrossRef]

45. MODIS MAIAC Water Vapor Download Page. Available online: https://ladsweb.modaps.eosdis.nasa.gov/ (accessed on 8 November 2021).

46. Raghavan, K.; Kumar, V.; Sugi, M.; Yoshimura, J. Internal Feedbacks from Monsoon-Midlatitude Interactions during Droughts in the Indian Summer Monsoon. J. Atmos. Sci. 2009, 66, 553-578. [CrossRef]

47. Monthly Atmospheric and Oceanic Climate Indices. Available online: https://psl.noaa.gov/data/climateindices/list/\#Nina34 (accessed on 8 November 2021).

48. JAMSTEC Website for Public Datasets. Available online: http://www.jamstec.go.jp/aplinfo/sintexf/e/index.html (accessed on 8 November 2021).

49. IRI Website for MJO. Available online: https://iridl.ldeo.columbia.edu/SOURCES/.BoM/.MJO/.RMM/index.html?SetLanguage=en (accessed on 8 November 2021).

50. Monsoon Monitoring Page for Monthly Datasets. Available online: http://apdrc.soest.hawaii.edu/projects/monsoon/seasonalmonidx.html (accessed on 8 November 2021).

51. South Asian Monsoon Indices Download Page. Available online: http://ljp.gcess.cn/dct/page/65544 (accessed on 8 November 2021).

52. Kumar, V.; Sunilkumar, K.; Sinha, T. Proportional Trends of Continuous Rainfall in Indian Summer Monsoon. Remote Sens. 2021, 13, 398. [CrossRef]

53. Sunilkumar, K.; Narayana Rao, T.; Satheeshkumar, S. Assessment of small-scale variability of rainfall and multi-satellite precipitation estimates using measurements from a dense rain gauge network in Southeast India. Hydrol. Earth Syst. Sci. 2016, 20, 1719-1735. [CrossRef]

54. Li, Z.; Lau, W.K.-M.; Ramanathan, V.; Wu, G.; Ding, Y.; Manoj, M.G.; Liu, J.; Qian, Y.; Li, J.; Zhou, T.; et al. Aerosol and monsoon climate interactions over Asia. Rev. Geophys. 2016, 54, 866-929. [CrossRef] 
55. Halder, S.; Dirmeyer, P.A. Relation of Eurasian Snow Cover and Indian Summer Monsoon Rainfall: Importance of the Delayed Hydrological Effect. J. Clim. 2017, 30, 1273-1289. [CrossRef]

56. Liu, S.; Duan, A. Impacts of the leading modes of tropical Indian Ocean sea surface temperature anomaly on sub-seasonal evolution of the circulation and rainfall over East Asia during boreal spring and summer. J. Meteorol. Res. 2017, 31, 171-186. [CrossRef]

57. Liu, F.; Chai, J.; Wang, B.; Liu, J.; Zhang, X.; Wang, Z. Global monsoon precipitation responses to large volcanic eruptions. Sci. Rep. 2016, 6, 24331. [CrossRef]

58. Ding, Z.; Lu, R.; Wang, Y. Spatiotemporal variations in extreme precipitation and their potential driving factors in non-monsoon regions of China during 1961-2017. Environ. Res. Lett. 2019, 14, 024005. [CrossRef]

59. Sardeshmukh, P.D.; Compo, G.P.; Penland, C. Need for Caution in Interpreting Extreme Weather Statistics. J. Clim. 2015, 28, 9166-9187. [CrossRef]

60. Wang, Z.; Chang, C.-P. A Numerical Study of the Interaction between the Large-Scale Monsoon Circulation and Orographic Precipitation over South and Southeast Asia. J. Clim. 2012, 25, 2440-2455. [CrossRef]

61. Argüeso, D.; Romero, R.; Homar, V. Precipitation Features of the Maritime Continent in Parameterized and Explicit Convection Models. J. Clim. 2020, 33, 2449-2466. [CrossRef]

62. Huang, A.; Zhou, Y.; Zhang, Y.; Huang, D.; Zhao, Y.; Wu, H. Changes of the annual precipitation over central Asia in the twenty-first century projected by multimodels of CMIP5. J. Clim. 2014, 27, 6627-6646. [CrossRef]

63. Miyan, M.A. Droughts in Asian Least Developed Countries: Vulnerability and sustainability. Weather Clim. Extrem. 2015, 7, 8-23. [CrossRef]

64. Muller, C.; Back, L.; O'Gorman, P.; Emanuel, K. A model for the relationship between tropical precipitation and column water vapor. Geophys. Res. Lett. 2009, 36, 16804. [CrossRef]

65. Kunkel, K.E.; Karl, T.R.; Squires, M.F.; Yin, X.; Stegall, S.T.; Easterling, D.R. Precipitation Extremes: Trends and Relationships with Average Precipitation and Precipitable Water in the Contiguous United States. J. Appl. Meteorol. Climatol. 2020, 59, 125-142. [CrossRef]

66. Seo, Y.-W.; Kim, H.; Yun, K.-S.; Lee, J.-Y.; Ha, K.-J.; Moon, J.-Y. Future change of extreme temperature climate indices over East Asia with uncertainties estimation in the CMIP5. Asia-Pac. J. Atmos. Sci. 2014, 50, 609-624. [CrossRef]

67. Bollasina, M.A.; Messori, G. On the link between the subseasonal evolution of the North Atlantic Oscillation and East Asian climate. Clim. Dyn. 2018, 51, 3537-3557. [CrossRef]

68. Chen, W.; Feng, J.; Wu, R. Roles of ENSO and PDO in the Link of the East Asian Winter Monsoon to the following Summer Monsoon. J. Clim. 2013, 26, 622-635. [CrossRef]

69. Krishnamurthy, L.; Krishnamurthy, V. Influence of PDO on South Asian summer monsoon and monsoon-ENSO relation. Clim. Dyn. 2014, 42, 2397-2410. [CrossRef] 